UC3M Working papers

Economics

15-04

ISSN 2340-5031

February 2015
Departamento de Economía

Universidad Carlos III de Madrid

Calle Madrid, 126

28903 Getafe (Spain)

Fax (34) 916249875

\title{
Risk Selection under Public Health Insurance with Opt-out
}

\author{
Sebastian Panthöfer* \\ Universidad Carlos III de Madrid \\ spanthoefer@gmail.com \\ February 18, 2015
}

\begin{abstract}
This paper studies risk selection between public and private health insurance when some individuals can purchase private insurance by opting out of otherwise mandatory public insurance. Using a theoretical model, I show that public insurance is adversely selected when insurers and insureds are symmetrically informed about health-related risks, and that selection can be of any type (advantageous or adverse) when insureds have private information about health risks. Drawing on data from the German Socio-Economic Panel, I find that: (1) public insurance is adversely selected under the German public health insurance with opt-out scheme, (2) individuals adversely select public insurance based on self-assessed health and advantageously select public insurance based on risk aversion, and (3) there is evidence of asymmetric information.
\end{abstract}

Keywords: Public and private health insurance, risk selection, asymmetric information

JEL classification: D82, H51, I13, I18

\footnotetext{
I am grateful to Matilde Machado for continued advice and support, and to Sebastian Bauhoff, María Inés Berniell, Jesús Carro, Luis Corchón, Anett Erdmann, Natalia Fabra, Andrés García-Suaza, Ángel HernandoVeciana, Federico Masera, Jan Nimczik, Kathleen Nosal, Achim Wambach, and participants of the 5th ASHEcon Conference, CDSE Seminar Mannheim, Madrid Microeconomics Graduate Workshop, and the UC3M 3rd-year Workshop for helpful comments. Financial support from the Spanish Plan Nacional de I+D+I (ECO2012-31748) is gratefully acknowledged.
} 


\section{Introduction}

Both mandatory public health insurance and freely competitive markets for private health insurance have their disadvantages. Public health insurance does not leave much room for consumer choice, often constituting a one-size-fits-all policy. In response to inadequate coverage in public insurance, individuals turn to private insurers and end up holding two health insurance policies. ${ }^{1}$ Private health insurers, on the other hand, are primarily interested in maximising profits. If they operate in a freely competitive market, there may be too little pooling of risks and not enough access to health insurance from a social point of view. The issue of limited access to health insurance can become severe in the presence of asymmetric information between insurers and insureds, which may manifest itself in contracts with too little coverage (Rothschild and Stiglitz 1976) or in a complete break down of some segments of the insurance market (Akerlof 1970).

Public health insurance with opt-out represents a middle ground between public and private health insurance: a contribution-financed public plan with income-dependent premiums coexists with a market for substitutive private health insurance, in which insurers offer riskrated contracts. I focus on the German public health insurance with opt-out scheme, which ties the possibility to opt out of public insurance to income: low-income earners are mandated to stay in public insurance, whereas high-income earners can choose between public and private insurance. ${ }^{2}$ Under this system, low-income earners are protected from not being able to purchase health insurance, and those who have the opportunity to choose between public and private health insurance have to pay higher premiums in case they decide to remain publicly insured than those who cannot choose.

The success of public health insurance with opt-out depends on the risk selection between public and private insurance. The difference in premium calculation is expected to lead to adverse selection against public insurance based on observables, because those who are observably high risk face low relative premiums in public insurance. On top of that, there could be adverse selection against public insurance based on unobservables, which may result from the fact that private insurers have the ability to screen applicants, through offering menus of contracts, whereas public insurance is a single policy. If private insurers are successful at selecting the best risks, then premiums in public insurance have to increase, at the expense of the low-income earners, who are mandated to stay in public insurance. ${ }^{3}$

\footnotetext{
${ }^{1}$ For example, $44.9 \%$ of the population in Australia, $15.6 \%$ in Italy, and $10 \%$ in the UK have some form of private health insurance, although all of these countries run a tax-financed public health insurance system that covers the entire population (Colombo and Tapay 2004). A significant amount of these private policies is duplicative, i.e., offering coverage for health services which are already included under the public plan.

${ }^{2}$ Apart from Germany, public health insurance with opt-out is also employed in Latin America, e.g. in Argentina, Chile, Colombia, and Peru. These countries grant the right to opt out of public insurance primarily to self-employed individuals, albeit buying private insurance is implicitly also related to income.

${ }^{3}$ Though this is not the topic of this paper, one may also object that the pool of risks that are allowed
} 
In this paper, I examine risk selection under public health insurance with opt-out. I begin by constructing a theoretical model in which a public plan coexists along with a competitive market for private health insurance. The model predicts that the type of selection depends on the informational scenario. Under symmetric information, selection against the public plan is necessarily adverse: the high-income earners who are high risk stay in public insurance, to receive implicit subsidies from the low-income earners, while the less risky high-income earners opt out and buy private insurance. Under asymmetric information, selection into public insurance can be adverse or advantageous. Selection can be advantageous because private insurers, in order to screen applicants, offer less insurance coverage to healthier individuals. This can lead to a situation in which some good risks, who are offered relatively little coverage in private insurance, stay in public insurance, whereas some bad risks, who are offered relatively generous coverage in private insurance, opt out of public insurance.

Drawing on data from the Socio-Economic Panel (SOEP), I provide empirical evidence on risk selection under public health insurance with opt-out in Germany. In a first step, I estimate a bivariate probit model of health insurance choice and health care utilisation, similar in spirit to the standard positive correlation test due to Chiappori and Salanié (2000). This model allows me to separately identify selection on observables and selection on unobservables. The key to isolating selection from moral hazard, thus overcoming one of the main shortcomings of the positive correlation test, is the choice of hospitalisation as the measure of health care utilisation. Hospitalisations are generally thought to be less susceptible to moral hazard, and I provide credible evidence showing that there is no moral hazard in hospitalisations in the German health insurance system. I then turn to identifying sources of selection on unobservables, following the approach of Finkelstein and Poterba (2014): I exploit that the SOEP contains a rich set of unused observables, variables that are observed by the econometrician but which insurers do not observe or do not use in the premium calculation, and test whether these unused observables are correlated with both health insurance choice and health care utilisation after controlling for the insurer risk classification. Finally, I test for asymmetric information in private health insurance by exploiting the theoretical model's predictions for the two informational scenarios.

I find that, overall, public insurance is adversely selected on both observables and unobservables. Not only is public insurance adversely selected based on observables which are directly related to health, such as pre-existing chronic conditions and disability status, but also based on other observable insuree characteristics, such as marital and self-employment status, which affect health insurance choice through institutional incentives. Regarding the sources of selection on unobservables, I find that individuals adversely select public insurance based on self-assessed health, which suggests that private insurers succeed in screening

to choose between public and private health insurance is better than the pool of risks that are mandated to stay in public insurance, which is the case if there is a positive correlation between income and health. 
their applicants through offering menus of contracts. I also find that risk-adverse individuals advantageously select public insurance, which has been observed before in other contexts, e.g. in the U.S. long-term care insurance market. A back-of-the-envelope calculation suggests that selection on observables accounts for approximately one third of the total adverse selection against public insurance, while the remaining two thirds are accounted for by selection on unobservables. Finally, I present evidence suggesting that the relationship between unobserved health status and health insurance choice is nonmonotone, which, according to the theoretical model, indicates the presence of asymmetric information.

This paper is related to several distinct literatures. The theoretical model relates closely to Olivella and Vera-Hernández (2013), who incorporate a public insurance plan into the canonical model of a competitive health insurance market due to Rothschild and Stiglitz (1976). The main difference between their model and the model presented in this paper lies in the financing of the public plan: Olivella and Vera-Hernández (2013) consider a taxfinanced public plan, whereas I study a contribution-financed public plan. Under the latter, the price of public insurance varies endogenously with the characteristics of those individuals who choose public insurance. Hindriks and De Donder (2003) and Goulão (2015) use a model similar to the one presented below to study the political support for public insurance when the market for private insurance is riddled with adverse selection.

This paper moreover contributes to the literature on selection between a public option and competing private health insurance plans. One widely studied example in this literature is the choice of elderly citizens in the U.S. between traditional fee-for-service Medicare and private Medicare Advantage (MA) plans. Brown et al. (2014) document that individuals who switch into MA plans turn out to be significantly less costly than observationally equivalent individuals who stay in traditional Medicare. Newhouse et al. (2012) investigate how changes to the risk adjustment formula and restrictions on switches have affected selection on unobservables in the Medicare program. They conclude that selection has been reduced but not eliminated. Two recent empirical studies analyse the German health insurance system: Grunow and Nuscheler (2014) study switches between public and private health insurance and find that individuals who have experienced a negative health shock show an increased propensity to leave private insurance. Bünnings and Tauchmann (2014) investigate the decision to opt out of public insurance and find that young and healthy individuals are disproportionately more likely to opt out of public insurance. Both studies point towards adverse selection against public insurance, but they do not relate health insurance choice with realised risk events and do not distinguish between selection on observables and selection on unobservables. I expand on the existing work by distinguishing between the two forms of selection, which allows for a comparison with the evidence from other countries, and moving beyond providing descriptive evidence of switchers to a formal test of selection.

Finally, this paper is also related to the literature on testing for asymmetric informa- 
tion in insurance markets. The starting point for this literature has been the insight that standard models of asymmetric information predict a positive correlation between insurance coverage and realised risk ex post (Chiappori and Salanié 2000). However, initial studies were unable to document such positive correlation and could therefore not reject the absence of symmetric information. Motivated by these early results, follow-up studies have considered multidimensional private information and selection on multiple contract dimensions. Cohen and Siegelman (2010) and Einav et al. (2010) survey the literature on testing for asymmetric information in insurance markets, to which I contribute by providing a test of asymmetric information in the context of a public health-insurance with opt-out system.

The rest of the paper is structured as follows. Section 2 lays out the theoretical model. Section 3 summarises relevant institutional details of the German health insurance system. Section 4 describes the data. Section 5 details the empirical approach and reports the evidence on selection and asymmetric information. Section 6 concludes. All proofs are delegated to an Online Appendix.

\section{A Model of Public Health Insurance with Opt-Out}

The private insurance market is based on the Rothschild and Stiglitz (1976) framework. As in Olivella and Vera-Hernández (2013), a public insurance plan coexists along with private insurance. Individuals must choose exactly one insurance policy, be it public or private. Private insurers observe some categorical information about insurance applicants and are allowed to discriminate prices based on these observables. The model presented below describes the market for health insurance within a risk class, in which individuals are observably equivalent. As such, the model's predictions concern the selection between public and private insurance based on unobservables.

There is a measure one of individuals who differ along two dimensions: their probability of becoming sick and their income. There are $n \geq 2$ different risks, $0<p_{1}<\ldots<p_{n}<1$, where $p_{i}$ is the probability with which an illness occurs, and two levels of income, $y_{H}>y_{L}$. Under symmetric information, a consumer's probability of falling sick is publicly observable, whereas it is private to the consumer under asymmetric information. Incomes are publicly observable. In the case of falling sick, individuals suffer a monetary loss $d<y_{L}$, against which they can insure themselves. The right to opt out of public insurance is granted based on income. Individuals who earn the low income $y_{L}$ are mandatorily insured in public insurance, while individuals who earn the high income $y_{H}$ can stay in public insurance or opt out and buy private insurance instead.

Low-income earners play only a subordinated role given that they do not choose their insurance contract. They are completely characterized by three parameters: their fraction of the population, $0<\lambda_{L}<1$, their income, $y_{L}$, and their average risk, $p_{L}$, where $p_{1} \leq p_{L} \leq p_{n}$. 
The fraction of individuals who earn the high income and are of risk $p_{i}$ is denoted by $\lambda_{i}$, where $\lambda_{i}>0$ for all $i \in\{1, \ldots, n\}$. The fraction of high-income earners in the population is $\sum_{i=1}^{n} \lambda_{i}=1-\lambda_{L}$. Henceforth, I refer to an individual with risk $p_{i} \in\left\{p_{1}, \ldots, p_{n}\right\}$ and income $y_{H}$ as a type $p_{i}$, or simply as $p_{i}$.

An insurance contract is a vector $I=(\alpha, \beta)$, where $\alpha$ is the insurance premium and $\beta$, $d \geq \beta \geq 0$, is the indemnity paid in case of an accident. Expected utility of type $p_{i}$ holding insurance policy $I=(\alpha, \beta)$ is given by

$$
U\left(I, p_{i}\right)=p_{i} u\left(y_{H}-d+\beta-\alpha\right)+\left(1-p_{i}\right) u\left(y_{H}-\alpha\right),
$$

where $u$ is strictly increasing, strictly concave, and twice continuously differentiable.

The public insurance plan $I^{p u b}=(\tau y, \eta d)$ is announced at the outset and constitutes a committed offer. It entails the contribution rate $\tau$, which multiplied by the income yields the insurance premium, and the coverage level $\eta$, which is the fraction of the damage that will be repaid in case of an accident. Public health insurance entails two forms of redistribution: from the rich to the poor, as premiums increase with income, and from the healthy to the sick, as premiums do not depend on risk. Public insurance is financed through the contributions of its members. To maintain a balanced budget, the government must set the contribution and replacement rates such that revenues equal expected cost:

$$
\tau\left(\lambda_{L} y_{L}+\sum_{i=1}^{n} \lambda_{i} s\left(p_{i}\right) y_{H}\right)=\eta d\left(\lambda_{L} p_{L}+\sum_{i=1}^{n} \lambda_{i} s\left(p_{i}\right) p_{i}\right)
$$

where $s\left(p_{i}\right)$ equals one (zero) if type $p_{i}$ joins public insurance (private insurance).

After the public plan is announced, $m \geq 2$ private insurers simultaneously offer contracts. Private insurers are risk neutral, incur no administrative cost, and expect the following profit from selling the contract $I=(\alpha, \beta)$ to type $p_{i}$ :

$$
\pi\left(I, p_{i}\right)=\alpha-p_{i} \beta
$$

Observing the menu of insurance plans available to them, high-income earners maximise their expected utility by choosing between public and private insurance. ${ }^{4}$ The following tiebreaking assumption is made to avoid the indeterminacy of the equilibrium strategy profile which arises in the knife-edge case in which one type is indifferent between public and private insurance.

Assumption 1. A high-income earner who is indifferent between public insurance and the best available private insurance contract chooses public insurance.

\footnotetext{
${ }^{4}$ High-income earners compare the public plan with the best private contract which is available.
} 
Equilibrium of the health insurance market is defined as follows.

Definition 1. An equilibrium is a strategy profile $s^{*}=\left[s^{*}\left(p_{i}\right)\right]_{i \in\{1, \ldots, n\}}$ and a set of contracts $C^{*}$, which includes the public plan, such that:

1. Every contract in $C^{*}$ is selected by some consumer.

2. No contract in $C^{*}$ yields negative profits.

3. There is no single contract outside of $C^{*}$ that, if offered, will be selected by consumers and will generate nonnegative profits for the insurer.

4. For $i \in\{1, \ldots, n\}: s^{*}\left(p_{i}\right)=1$ if $I^{p u b} \in \arg \max _{I \in C^{*}} U\left(I, p_{i}\right)$, and $s^{*}\left(p_{i}\right)=0$ otherwise.

5. The government budget is balanced: (1) holds when $s=s^{*}$.

The first three conditions are analogous to Rothschild and Stiglitz (1976). The fourth condition requires high-income earners to decide optimally between public and private insurance, and the fifth condition guarantees that the public budget is balanced in equilibrium.

Following Einav et al. (2010), I say that the public plan is adversely selected if the expected cost of insuring the high-income earners who choose public insurance in equilibrium is higher than the expected cost of insuring the population of high-income earners.

Definition 2. The public plan, $I^{p u b}$, is adversely selected if

$$
\mathbb{E}_{p}\left[p d \mid s^{*}(p)=1\right]>\mathbb{E}_{p}[p d]
$$

Conversely, I say that there is advantageous selection into public insurance if the reverse inequality holds.

\subsection{Equilibrium under Symmetric Information}

Consider first the market for private health insurance. Under symmetric information, private insurers know the risk of each applicant and can offer a corresponding contract. Following Rothschild and Stiglitz (1976), competition drives insurance companies to offer $n$ actuarially fair contracts, one for each type, with full coverage of damages in case of an accident.

When deciding between public and private health insurance, the high-income earners take into account two factors: the level of coverage under public insurance and the publicprivate premium differential. The level of coverage under public insurance matters because individuals are risk averse and prefer full insurance at actuarially fair or favourable odds. The public-private premium differential is the difference in the price of one unit of coverage under public and private insurance. For a given type $p_{i}$, the premium differential is determined 


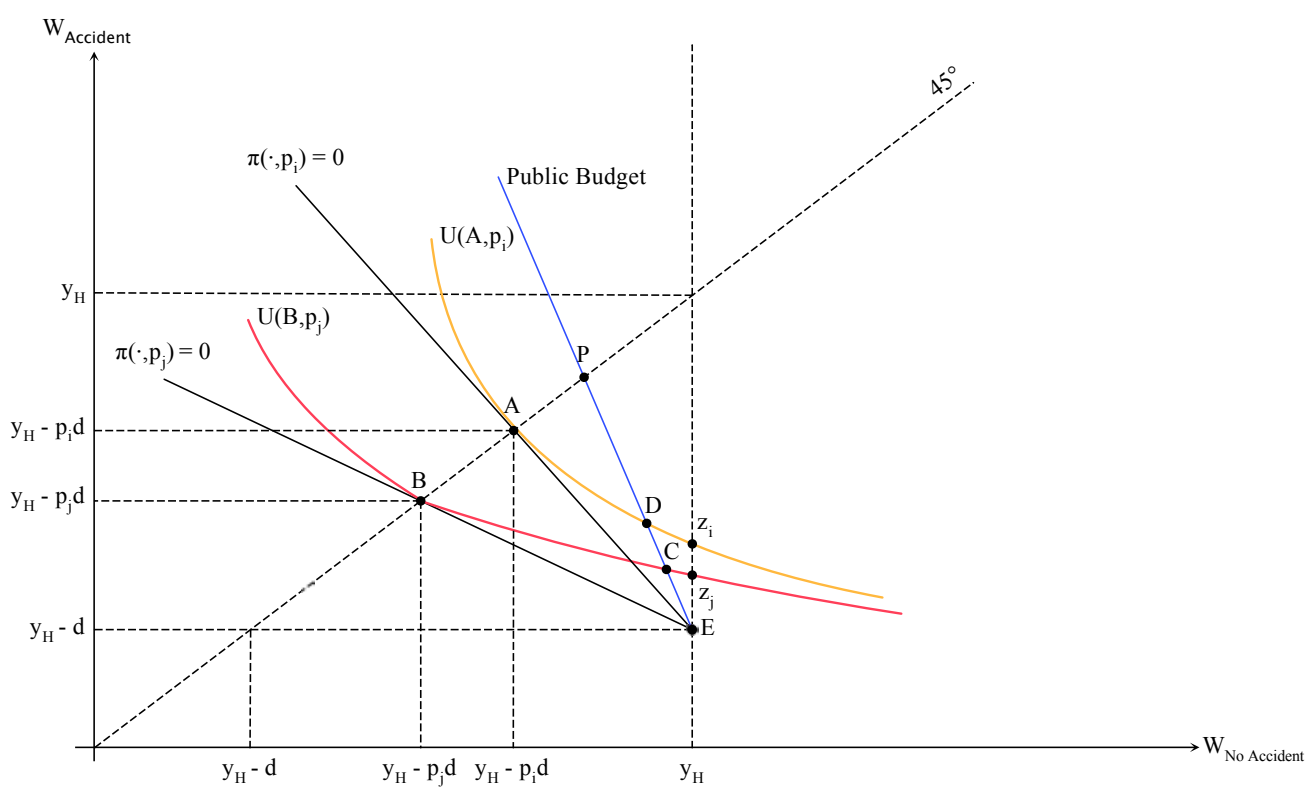

Notes: $A=\left(p_{i} d, d\right)$ and $B=\left(p_{j} d, d\right)$, respectively, are the private insurance contracts offered to two risks $p_{i}$ and $p_{j}$, where $p_{i}<p_{j}$. For a given contribution rate $\tau$, the public insurance contract lies on the line $E P$. The exact position on $E P$ depends on the level of coverage under the public plan. Full insurance corresponds to $P$ and no insurance to $E . z_{i}$ and $z_{j}$ are used in the proof of Lemma 1.

by the difference between incomes, which determines the amount of income redistribution, and the difference between $p_{i}$ and the average risk in public insurance, which determines the gains from risk pooling.

The following Lemma shows that the incentives to join public insurance are stronger for individuals with bad health, the intuition being that these individuals experience higher gains from risk pooling in public insurance.

Lemma 1. For any given public plan under symmetric information, if $p_{i}$ joins public insurance, then all types $p_{j}>p_{i}$ join public insurance.

After performing the standard change of variables (see the Online Appendix) in Figure 1 , the insurance contracts of two types $p_{i}<p_{j}$ are depicted in the space of final wealths. In the proof of Lemma 1, I show that the indifference curve of $p_{i}$ through his designated private insurance contract, $A$, lies strictly above the one of type $p_{j}$ through his designated private contract, $B$, in the insurance plane. Assuming that the public insurance budget is balanced on the line running through the points $E$ and $P$, we can see that both types join public insurance if the public plan is located on or above $D$, only $p_{j}$ joins public insurance if the public plan is located on or above $C$ and below $D$, and none of the two types joins public insurance if the public plan is located below $C$.

Lemma 1 leads the way to the health insurance market equilibrium. 
Proposition 1. The health insurance market equilibrium under symmetric information, if it exists, is unique and depends on the level of coverage under the public plan and the lowincome-earner characteristics. Two scenarios can occur in the equilibrium under symmetric information:

1. No entry into public insurance: $s^{*}=0$ and

$$
C^{*}=\left\{I^{p u b}=\left(\eta d \frac{p_{L}}{y_{L}} y, \eta d\right), I^{p r i v}=\left(p_{i} d, d\right)_{i \in\{1, \ldots, n\}}\right\} .
$$

2. Adverse selection against the public sector: there exists $j, 1<j \leq n$, such that $s^{*}\left(p_{i}\right)=$ 0 for all $i<j$ and $s^{*}\left(p_{k}\right)=1$ for all $k \geq j$, and

$$
C^{*}=\left\{I^{p u b}=\left(\eta d \frac{\lambda_{L} p_{L}+\sum_{k=j}^{n} \lambda_{k} p_{k}}{\lambda_{L} y_{L}+\sum_{k=j}^{n} \lambda_{k} y_{H}} y, \eta d\right), I^{\text {priv }}=\left(p_{i} d, d\right)_{i \in\{1, \ldots, j-1\}}\right\} .
$$

In the first case, even the high-income earners with the highest risk do not benefit from staying under the public plan. Consequently, all high-income earners use their right to opt out and buy private insurance. In the second case, some high-income earners choose public insurance. This case leads to adverse selection against public insurance because only the high risks remain in public insurance. Formally, $\mathbb{E}_{p}\left[p d \mid s^{*}(p)=1\right]=\mathbb{E}_{p}\left[p d \mid p \geq p_{j}\right]>\mathbb{E}_{p}[p d]$, where the inequality follows from $p_{j}>p_{1}$. The healthiest high-income earners (with risk $p_{1}$ ) never join public insurance in equilibrium because they can only lose from risk pooling.

The number of types who join public insurance in equilibrium, if any, depends as follows on the low-income-earner characteristics and the coverage under the public plan.

Proposition 2. In the equilibrium under symmetric information, more high-income earners join public insurance, ceteris paribus, the lower the risk of the average low-income earner $\left(p_{L}\right)$, the higher the low income $\left(y_{L}\right)$, the larger the fraction of low-income earners $\left(\lambda_{L}\right)$, and the higher the level of coverage under the public plan $(\eta)$.

Given that private insurers offer full insurance at actuarially fair odds, types who join public insurance necessarily find public insurance actuarially fair or favourable. Under this premise, more insurance is always better, explaining the fact that more types join public insurance if it offers more coverage. The low-income-earner characteristics affect the highincome earners' insurance choice through their impact on the public premium. In equilibrium, the public premium is an increasing function of the low-income-earner risk and a decreasing function of the low income and the share of low-income earners. The last result follows from the fact that only high-income earners with risk higher than the average low-income earner join public insurance in equilibrium, because only for these individuals are there gains from 
risk pooling. Consequently, an increase in the fraction of low-income earners reduces the average risk in public insurance and therefore also the price of public insurance.

Not always does a health insurance market equilibrium exist. There may arise a situation in which the government cannot set a budget-balancing contribution rate for a given level of coverage in public insurance. The nonexistence of equilibrium is unrelated to the tiebreaking assumption made above. Rather, it occurs because the distribution of types is discrete. Under a discrete distribution of types, the entry of any type has a discrete effect on the public budget. There may be a situation in which a certain type wants to join public insurance at a given contribution rate and coverage level, but if the government adjusts the contribution rate, to balance the budget for when this type joins public insurance, this type would no longer want to join public insurance.

Nonexistence of equilibrium can be circumvented, e.g., with a continuous distribution of types. With a continuum of types, the entry of any type into public insurance has a negligible impact on the public budget, therefore ruling out a situation as the one described above. However, a continuum of types greatly reduces the model's tractability, without altering its conclusions, at least in the symmetric information case. For this reason, I refrain from considering a continuum of types. Instead, I conduct the empirical analysis under the assumption that the health insurance market is in equilibrium.

\subsection{Equilibrium under Asymmetric Information}

Now consider the case in which the insureds are privately informed about their personal risk $\left(p_{i}\right)_{i \in\{1, \ldots, n\}}$, while the insurers only know the distribution of risks in the population $\left(\lambda_{i}\right)_{i \in\{1, \ldots, n\}}$. Let us focus first on the private sector and abstract away from the public plan for a moment. From Rothschild and Stiglitz (1976), we know that, in equilibrium, less risky types will be offered contracts with less generous coverage, competition drives profits on each contract down to zero, and contracts have to be separating (otherwise, there would exist a profitable deviation that lies in cream-skinning the good risks out of a pooling contract). We also know that local (downward) incentive-compatibility constraints are sufficient for separation if expected utility satisfies the Spence-Mirrlees strict single crossing property. ${ }^{5}$ Finally, we know that an equilibrium in pure strategies may fail to exist. ${ }^{6}$

The equilibrium properties of the private contract schedule remain basically unchanged in the presence of a public insurance plan. The difference is that, with a coexisting public plan, some incentive-compatibility constraints may not be determined by making a type indifferent between two private contracts, but between a private contract and the public plan.

When deciding between public and private insurance, high-income earners face the same

\footnotetext{
${ }^{5}$ Which it does, because $U_{\alpha}(I, \cdot) / U_{\beta}(I, \cdot)$ is strictly increasing for all $I$.

${ }^{6}$ With 2 types, the unique separating equilibrium ceases to exist when the share of low risks in the market is large. Riley (1985) establishes sufficient conditions for equilibrium existence in the case of $n \geq 2$ types.
} 
trade-off as under symmetric information. They weigh the difference in coverage between public and private insurance against the public-private premium differential. Only that now, under asymmetric information, coverage in private insurance is no longer necessarily higher than coverage in public insurance. This feature gives rise to the possibility of advantageous selection into public insurance.

The health insurance market equilibrium is characterised in the following proposition.

Proposition 3. The health insurance market equilibrium under asymmetric information, if it exists, depends on the level of coverage under the public plan and the low-income-earner characteristics. Three scenarios can occur in the equilibrium under asymmetric information:

1. No entry into public insurance: $s^{*}=0$ and

$$
C^{*}=\left\{I^{p u b}=\left(\eta d \frac{p_{L}}{y_{L}} y, \eta d\right), I^{p r i v}=\left(p_{i} \vartheta_{i} d, \vartheta_{i} d\right)_{i \in\{1, \ldots, n\}}\right\} .
$$

2. Adverse selection against the public sector: there exists $j, 1<j \leq n$, such that $s^{*}\left(p_{i}\right)=0$ for all $i<j$ and $s^{*}\left(p_{k}\right)=1$ for all $k \geq j$, and

$$
C^{*}=\left\{I^{p u b}=\left(\eta d \frac{\lambda_{L} p_{L}+\sum_{k=j}^{n} \lambda_{k} p_{k}}{\lambda_{L} y_{L}+\sum_{k=j}^{n} \lambda_{k} y_{H}} y, \eta d\right), I^{\text {priv }}=\left(p_{i} \vartheta_{i} d, \vartheta_{i} d\right)_{i \in\{1, \ldots, j-1\}}\right\} .
$$

3. Fragmentation of risks: there exist $j$ and $k, 1<j \leq k<n$, such that $s^{*}\left(p_{i}\right)=0$ for all $i<j, s^{*}\left(p_{r}\right)=1$ for all $j \leq r \leq k$ and $s^{*}\left(p_{l}\right)=0$ for all $l>k$, and

$$
C^{*}=\left\{I^{p u b}=\left(\eta d \frac{\lambda_{L} p_{L}+\sum_{r=j}^{k} \lambda_{r} p_{r}}{\lambda_{L} y_{L}+\sum_{r=j}^{k} \lambda_{r} y_{H}} y, \eta d\right), I^{p r i v}=\left(p_{i} \vartheta_{i} d, \vartheta_{i} d\right)_{i \in\{1, \ldots, j-1, k+1, \ldots, n\}}\right\}
$$

The equilibrium schedule of private contracts I $^{\text {riv }}$ satisfies the following: (i) uniqueness: $I^{\text {priv }}$ is unique, (ii) no distortion at the top: if $s^{*}\left(p_{n}\right)=0$, then $\vartheta_{n}=1$, (iii) distortion at the bottom: if $s^{*}\left(p_{i}\right)=0$ and $i<n$, then $\vartheta_{i}<1$, (iv) incentive compatibility: if $s^{*}\left(p_{i}\right)=$ $s^{*}\left(p_{i+1}\right)=0$, then $U\left[\left(p_{i+1} \vartheta_{i+1} d, \vartheta_{i+1} d\right), p_{i+1}\right]=U\left[\left(p_{i} \vartheta_{i} d, \vartheta_{i} d\right), p_{i+1}\right]$, and if $s^{*}\left(p_{i}\right)=0$ and $s^{*}\left(p_{i+1}\right)=1$, then $U\left(I^{p u b}, p_{i+1}\right)=U\left[\left(p_{i} \vartheta_{i} d, \vartheta_{i} d\right), p_{i+1}\right]$, (v) monotonicity: if $s^{*}\left(p_{i}\right)=s^{*}\left(p_{j}\right)=$ 0 and $j>i$, then $\vartheta_{j}>\vartheta_{i}$, and (vi) positive insurance: if $s^{*}\left(p_{i}\right)=0$, then $\vartheta_{i}>0$.

The first and second scenario also occur when all market participants are symmetrically informed. The third scenario is exclusive to asymmetric information, because only in the presence of asymmetric information do private insurers offer contracts which include less coverage for the good risks. This can lead to a situation where some bad risks, who are offered relatively generous coverage in private insurance, take up private insurance, while some less riskier types join public insurance, because they are offered only relatively little 
Figure 2. Equilibrium under Asymmetric Information with Fragmentation of Risks

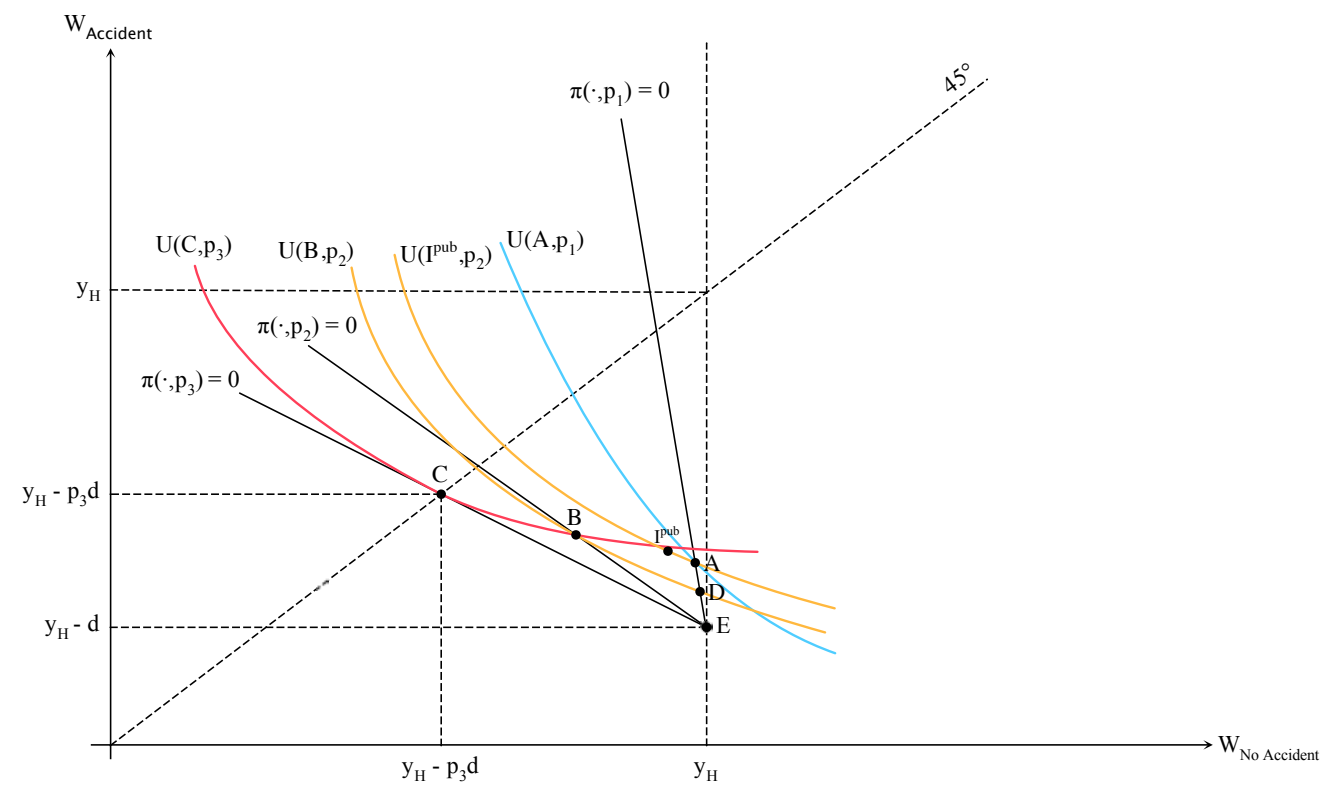

Notes: $A, B$, and $C$ are the incentive-compatible, actuarially fair private insurance contracts offered to types $p_{1}, p_{2}$, and $p_{3}$, respectively, where $p_{1}<p_{2}<p_{3} . I^{p u b}$ is the public plan. Types $p_{1}$ and $p_{3}$ prefer private over public insurance. Type $p_{2}$ prefers public over private insurance. The incentive-compatible contract for type $p_{1}, A$, is designed such that type $p_{2}$ is indifferent between this contract and public insurance. In the absence of a public plan, private insurers would offer the contract $D$ to type $p_{1}$.

coverage by private insurers. Notice also that, as under symmetric information, individuals of type $p_{1}$ never join public insurance.

Figure 2 illustrates the third scenario for the case of three types $p_{1}<p_{2}<p_{3}$. In equilibrium, type $p_{2}$ chooses public insurance, and types $p_{1}$ and $p_{3}$ purchase private insurance. The equilibrium set of contracts is given by $C^{*}=\left\{I^{p u b}, A, C\right\}$. Selection into public insurance can be adverse or advantageous, depending on the fractions of the three types. Formally, $\mathbb{E}_{p}\left[p d \mid s^{*}(p)=1\right]=p_{2} d$ and $\mathbb{E}_{p}[p d]=\left(\lambda_{1} p_{1}+\lambda_{2} p_{2}+\lambda_{3} p_{3}\right) d /\left(\lambda_{1}+\lambda_{2}+\lambda_{3}\right)$, so that the public plan is adversely selected if $\lambda_{1}\left(p_{2}-p_{1}\right)>\lambda_{3}\left(p_{3}-p_{2}\right)$ and advantageously selected if the reverse inequality holds. This example generalises to any number of types.

Corollary 1 summarises the model's predictions for the two informational scenarios. They provide the basis for the test of asymmetric information performed below.

Corollary 1. Suppose that some high-income earners choose public insurance in equilibrium. Under symmetric information, unobserved health status and the choice of insurance are monotonously related, leading to adverse selection against the public sector based on unobservables. Under asymmetric information, the relationship between unobserved health status and the choice of insurance can be monotone or U-shaped, and selection into public insurance based on unobservables can be adverse or advantageous. 
One final thing is left to notice. The existence of the public plan can lead to some types obtaining more comprehensive coverage than in a purely private health insurance market. In the example with three types, the incentive-compatible contract that can be offered to $p_{1}$ is $A$. In the absence of a public plan, private insurers must reduce the coverage for type $p_{1}$ to the level of contract $D$, in order to guarantee incentive compatibility. This interaction between public and private health insurance does not arise under symmetric information, where the public plan solely determines which of the private contracts are chosen in equilibrium.

\section{Public Health Insurance with Opt-out in Germany}

This section gives an overview over the German health insurance system and describes the institutional features that are relevant for the analysis to follow.

Germany imposes an individual health insurance mandate since 2009. Irrespective of the mandate, the number of uninsured has historically always been low. About $90 \%$ of the German population holds public health insurance, which is largely financed through the contribution of its members and provided by sickness funds, which operate on a non-profit basis. The remaining $10 \%$ of the population holds substitutive private health insurance. Roughly $75 \%$ of the population is mandatorily insured in public insurance. The other $25 \%$ can decide between opting out of public insurance and remaining voluntarily insured in the public system. Opting out of public insurance is possible when gross labor income is above the so-called compulsory insurance threshold (53,550 Euros in 2014), or when an individual is exempted based on his occupation. The two most important groups that are exempted from the public insurance mandate are civil servants and individuals in self-employment. Once an individual has decided to opt out of public insurance, reentry into the public system is restricted and becomes possible only when both criteria that determine the eligibility to opt out are no longer satisfied. ${ }^{7}$

The most important difference between public and private insurance is the premium calculation. Premiums in public insurance depend only on labor income: the publicly insured pay a fraction of their gross wage $(8.2 \%$ in 2014 , which is matched with a $7.3 \%$ contribution from the employer) up to the contribution ceiling, above which contributions are zero. Premiums in private insurance are risk rated and not tied to income. They are fixed at the initial enrollment and cannot be adjusted in response to health events after the signing of the contract, implying that private insurance clients are protected against reclassification risk. Private insurers also have no right to cancel an existing contract, unless premiums are not paid.

The risk rating in private insurance is conducted on the basis of mandatory health ques-

\footnotetext{
${ }^{7}$ Individuals aged 55 years or older can never switch from private to public health insurance.
} 
tionnaires. Most insurers elicit the same information from potential consumers. Applicants have to report height and weight, disability status, chronic diseases, pregnancy status, a potential HIV infection, ambulatory treatments within the last three years, stationary treatments within the last five years, prescribed pharmaceuticals within the last 3 years, absences from work which have lasted longer than 14 days during the last three years, and psychological therapies within the last 10 years. False reporting in the questionnaires can lead to withholding of benefits or termination of the contract.

Contract customisation is another important aspect in which public and private insurance differ. Private insurance customers can select a contract that is individually optimal. Private insurers typically offer several benefits packages and let customers choose the level of their annual deductible. Public insurance, on the other hand, offers little room for consumer choice. Almost all of the benefits that are covered by public health insurance are dictated by the regulator, and consumers also do not have much choice in changing the cost-sharing rules of their contract. The standard contract in public health insurance imposes little out-of-pocket expenses on its customers, mostly in the form of moderate co-payments for pharmaceuticals and hospital stays.

A few other personal characteristics besides health status determine the relative price between public and private insurance. The relative price of public insurance decreases with the age of the insured, not only because health deteriorates, but also because private insurers are legally mandated to build up old-age provisions in order to keep premiums constant over the life-cycle. As the time period over which these old-age provisions can be built up becomes shorter the older the applicant, private premiums have to increase. Public insurance is relatively cheap for families because non-working spouses and dependent children below 26 years of age are insured free of charge in public insurance. Women face a lower relative price of public insurance than men because private insurers charge women higher premiums. Civil servants pay a high relative price for public insurance because they and their dependent family members receive partial reimbursements of medical expenses through the so-called Beihilfe, which reduces the cost of private insurance by up to $80 \%$ but does not affect the price of public insurance. The relative price of public insurance increases with the income of selfemployed individuals and civil servants until the contribution ceiling is reached. Individuals who qualify to opt out of public insurance based on their income pay a fixed premium for public insurance, which does not depend on their actual income, because the compulsory insurance threshold lies above the contribution ceiling.

\section{Data and Descriptive Statistics}

The empirical analysis is based on data from the German Socio-Economic Panel (SOEP), a long-running panel which elicits annually information from a representative sample of German 
Table 1. Descriptive Statistics of Selected Variables

\begin{tabular}{|c|c|c|c|c|c|}
\hline \multicolumn{3}{|l|}{ Health measures } & \multicolumn{3}{|c|}{ Socio-economic factors } \\
\hline & Public & Private & & Public & Private \\
\hline Self-assessed health & $\begin{array}{c}3.594 \\
(0.831)\end{array}$ & $\begin{array}{c}3.717 \\
(0.792)\end{array}$ & Number of children & $\begin{array}{c}0.835 \\
(1.049)\end{array}$ & $\begin{array}{c}0.707 \\
(0.961)\end{array}$ \\
\hline Disability & $\begin{array}{c}0.054 \\
(0.225)\end{array}$ & $\begin{array}{c}0.021 \\
(0.143)\end{array}$ & Married & $\begin{array}{c}0.836 \\
(0.371)\end{array}$ & $\begin{array}{c}0.776 \\
(0.417)\end{array}$ \\
\hline Chronic illness & $\begin{array}{c}0.315 \\
(0.465)\end{array}$ & $\begin{array}{c}0.214 \\
(0.411)\end{array}$ & Female & $\begin{array}{c}0.254 \\
(0.436)\end{array}$ & $\begin{array}{c}0.220 \\
(0.414)\end{array}$ \\
\hline Hospitalised within a year & $\begin{array}{c}0.076 \\
(0.265)\end{array}$ & $\begin{array}{c}0.063 \\
(0.244)\end{array}$ & Age & $\begin{array}{l}44.737 \\
(8.535)\end{array}$ & $\begin{array}{l}44.156 \\
(8.342)\end{array}$ \\
\hline Doctor visits per quarter & $\begin{array}{c}1.785 \\
(3.078)\end{array}$ & $\begin{array}{c}1.474 \\
(2.938)\end{array}$ & Income & $\begin{array}{c}54,307 \\
(36,732)\end{array}$ & $\begin{array}{c}65,684 \\
(66,113)\end{array}$ \\
\hline $\begin{array}{l}\text { Sick leave }>6 \text { weeks } \\
\text { within a year }\end{array}$ & $\begin{array}{c}0.033 \\
(0.178)\end{array}$ & $\begin{array}{c}0.022 \\
(0.147)\end{array}$ & Self-employed & $\begin{array}{c}0.378 \\
(0.485)\end{array}$ & $\begin{array}{c}0.614 \\
(0.487)\end{array}$ \\
\hline Observations & 16,881 & 9,765 & Observations & 16,881 & 9,765 \\
\hline
\end{tabular}

Notes: Means and standard deviations (in parentheses) are calculated based on all observations from 1999 to 2011 of individuals aged 20 to 60 who are eligible to purchase private insurance, not insured through one of their family members, and not receiving subsidies towards private insurance as a civil servant. Two-sided t-tests reject the null hypothesis of no difference in means between public and private insurance at the $1 \%$ level of significance for all variables. Number of observations varies by variable and sample.

households. At the individual level, the SOEP contains subjective and objective health measures, health insurance details, as well as a wide array of socio-economic information.

The sample period consists of the years from 1999 to 2011. Observations from prior to 1999 had to be excluded because important covariates are missing. The sample consists of individuals aged 20 to 60 who are eligible to purchase private insurance, not insured through one of their family members, and not receiving subsidies towards private insurance through being a civil servant or a dependent relative of a civil servant. Individuals under 20 years of age are excluded to avoid distortions which may arise due to family insurance. Individuals above the age of 60 are excluded to avoid distortions arising from various retirement schemes. Individuals who are insured through one of their family members are not considered because they do not make an active decision. Civil servants and their relatives are excluded because their choice of health insurance is fundamentally different from the rest of the population due to the subsidies they receive: almost all civil servants choose private health insurance, no matter whether they are in good or bad health. The final sample consists of 26,646 personyear observations from 6,691 individuals. Individuals in the sample are either self-employed or dependent workers with incomes above the compulsory insurance threshold. 
Table 1 contains means and standard deviations (in parentheses) of selected variables. From these statistics, we can infer that private and public insurance clients are remarkably different in terms of health status. The privately insured report to be of better health, are less likely to be disabled, have a lower prevalence of chronic illnesses, and are less likely to take a sick leave of more than six weeks. The privately insured also use less medical services: they go less often to the doctor and are less likely to be hospitalised.

Private and public insurance clients differ also with respect to their socio-economic characteristics. Private insurance clients are less likely to be married or female, and, on average, they are younger and have less children. These factors are hardly a surprise given the institutional incentives. Largely due to the income threshold, privately insured individuals also have substantially higher incomes. Lastly, there is a higher share of self-employed individuals among the privately insured than among the publicly insured.

\section{Evidence on Selection and Asymmetric Information}

In this section, I present evidence on the nature and magnitude of selection between public and private health insurance in Germany. I show that there is considerable adverse selection against the public sector, based on both observables and unobservables, and identify sources of selection on unobservables. I further show that there is suggestive evidence pointing towards the existence of informational asymmetries between insurers and insureds.

\section{$5.1 \quad$ Empirical Approach}

The first goal of the analysis that follows is to distinguish between selection based on observables, which is due to the fact that public health insurance providers, unlike private health insurance providers, are not allowed to risk adjust premiums, and selection based on unobservables, which is the selection within classes of observationally equivalent individuals. The two forms of selection can be identified separately by controlling for variables that private insurers use to classify risks. These risk classification variables are included as independent variables in a bivariate probit model of health care utilization and health insurance choice, similar in spirit to the standard positive correlation test for asymmetric information (Chiappori and Salanié 2000). With this approach, selection based on observables is captured by the coefficient vector associated to the insurer risk classification, and selection based on unobservables is captured by the correlation of the residuals.

However, as is well-known, the positive correlation test does not distinguish between moral hazard and adverse selection. To single out the effect of selection, I use a measure for the utilisation of medical services that is arguably free of moral hazard: hospitalisation. ${ }^{8}$

\footnotetext{
${ }^{8}$ Early empirical support for this hypothesis stems from the famous RAND Health Insurance Experiment,
} 
Patients generally do not choose whether to become hospitalised or not considering the financial consequences of the hospitalisation: Frequently, the patient's medical condition may be so severe that a hospitalisation is inevitable. In other cases, it is the doctor who administers the hospitalisation decision.

More generally, the validity of my approach requires that hospitalisations do not depend on health insurance status (public or private) other than through selection, which I assume to be the case in the following. I return to this assumption in Section 5.5, after presenting the empirical results, and provide evidence which strongly suggests that the assumption is valid in the context of the SOEP data.

With respect to the second equation of the bivariate probit model, I follow Bünnings and Tauchmann (2014) and model health insurance choice as a hazard model in discrete time with private insurance as the absorbing state: in each period, an individual either survives (stays in public insurance), fails (switches to private insurance), or drops out of the sample (no longer qualifies to purchase private insurance). German legislation dictates the choice of such a hazard model, because it generally restricts private insurance clients to stay in private insurance. During the sample period, 741 individuals (out of 6,691 in the sample) opt out of public insurance and become privately insured.

After presenting the results from the basic bivariate probit model of health insurance choice and health care utilisation, I turn to identifying sources of selection on unobservables (following Finkelstein and Poterba 2014) and testing for asymmetric information. To conclude the empirical part, I present an alternative approach to measuring selection, discuss potential confounding factors, and offer a sensitivity analysis of the results.

\subsection{Selection on Observables}

The following bivariate probit model is employed to measure selection on observables:

$$
\begin{aligned}
\text { OPTOUT }_{i t} & =\mathbf{1}\left(a_{1}+b_{1} X_{i t}+e_{1 i t}>0\right) . \\
\text { HOSPITAL }_{i t+1} & =\mathbf{1}\left(a_{2}+b_{2} X_{i t}+e_{2 i t}>0\right) .
\end{aligned}
$$

OPTOUT $_{i t}$ is a binary variable that captures the choice of individual $i$ to opt out of public insurance in period $t$ conditional on being eligible to opt out. $\mathrm{HOSPITAL}_{i t+1}$ is a binary variable that equals one if individual $i$ is hospitalised in period $t+1 . X_{i t}$ is a vector of attributes of individual $i$ that determine the relative price between private and public insurance at time $t{ }^{9}$ I will refer to $X$ as the insurer risk classification.

which did not find evidence of moral hazard in inpatient spending (Manning et al. 1987). Recent studies have capitalised on this result and related findings to test for adverse selection in health insurance (Olivella and Vera-Hernández 2013, de la Mata et al. 2014).

${ }^{9} X$ contains disability status, an indicator of chronic illness, the number of hospitalisations within the last five years, doctor visits per quarter within the last three years, an indicator of body mass index (BMI) 
The error terms $e_{i t}=\left(e_{1 i t}, e_{2 i t}\right)$ are assumed to be independently, identically, and normally distributed across individuals. They may, however, be correlated over time for a given individual. I address this issue in two ways. In the main analysis, I will estimate a pooled bivariate probit model and compute the standard errors using a block bootstrap procedure with clustering at the individual level, allowing for valid inference in the presence of serially correlated errors. As a robustness check and in order to guarantee that the pooled probit estimates are not driven by repeated observations on individuals who do not actively decide about their health insurance policy, I reestimate the model on the subsample of individuals who are in the first or second year of being eligible to choose private insurance.

In the bivariate probit model of equations (2) and (3), selection on observables is captured by the coefficient vector $b=\left(b_{1}, b_{2}\right)$ associated to the insurer risk classification. Variables contained in $X$ that enter equations (2) and (3) with coefficients of opposite sign are a cause of adverse selection against public insurance based on observables.

The estimates presented in Table 2 indicate that public insurance is adversely selected based on several health-related observables. Individuals who have had a health event in the past that required a doctor visit or a hospitalisation, women of child-bearing age, and individuals who are old, chronically ill, or disabled are less likely to opt out of public insurance, which is in line with earlier findings by Bünnings and Tauchmann (2014). Moreover, exactly these characteristics also render a future hospitalisation more likely. Taken together, these two results imply that the public sector is adversely selected based on these health-related observables.

On top of the selection on health-related observables, there is also evidence of adverse selection against the public sector based on observables that are not directly related to health, such as marital status, self-employment, and the income of self-employed individuals. These variables affect the choice of health insurance as expected, in line with the regulatory incentives. However, except for the positive correlation between the income of self-employed individuals and health status, there was a priori no reason to believe that the aforementioned variables also have a negative impact on the public sector in terms of subsequent hospitalisations, resulting in further adverse selection against public insurance.

There are three exceptions to this pattern of adverse selection against the public sector based on observables: obesity, sick leaves, and the number of children. Individuals who are above 30, absences from work for more than 6 weeks within the last three years, number of children, marital status, gender, an indicator of being a women of child-bearing age, four indicators capturing age, an indicator of self-employment, an interaction term between self-employment and the natural logarithm of income, and a set of year indicators. The year indicators are included to capture changes in the public premiums, which occur almost every year. All variables, apart from the chronic illness indicator and the obesity indicator, are predetermined. The chronic illness indicator equals one if an individual reports to suffer from a chronic disease in at least one of the three years from 2009 to 2011, which are the only years for which this information is available. The obesity indicator equals one if the average BMI over the years 2002, 2004, 2006, 2008, and 2010 of a person is above 30. To the extent that chronic conditions and BMI do not fluctuate much over time, these two indicators represent a reasonable approximation of the missing values. 
Table 2. Selection on Observables

\begin{tabular}{lllll}
\hline \hline & & & & \\
Dependent variable: & OPTOUT & \multicolumn{3}{l}{ HOSPITAL } \\
\hline Disability status & -0.006 & $(0.014)$ & $0.034^{* *}$ & $(0.013)$ \\
Chronic illness & $-0.012^{* *}$ & $(0.005)$ & $0.029^{* * *}$ & $(0.007)$ \\
Hospitalised last 5 years & -0.008 & $(0.010)$ & $0.041^{*}$ & $(0.022)$ \\
Doctor visits last 3 years & $-0.004^{* *}$ & $(0.002)$ & $0.006^{* * *}$ & $(0.001)$ \\
BMI $>30$ & 0.001 & $(0.007)$ & 0.004 & $(0.009)$ \\
Sick leave $>6$ weeks last 3 years & 0.015 & $(0.018)$ & 0.018 & $(0.025)$ \\
Children & $-0.011^{* * *}$ & $(0.003)$ & $-0.009^{* *}$ & $(0.003)$ \\
Married & $-0.012^{* *}$ & $(0.006)$ & $0.025^{* *}$ & $(0.010)$ \\
Female & 0.006 & $(0.007)$ & -0.011 & $(0.010)$ \\
Female 20-39 & -0.011 & $(0.010)$ & $0.050^{* * *}$ & $(0.015)$ \\
Age 20-29 (omitted) & - & - & - & - \\
Age 30-39 & $-0.033^{* * *}$ & $(0.008)$ & 0.017 & $(0.017)$ \\
Age 40-49 & $-0.066^{* * *}$ & $(0.009)$ & 0.010 & $(0.018)$ \\
Age 50-60 & $-0.082^{* * *}$ & $(0.010)$ & 0.026 & $(0.019)$ \\
Self-employed & -0.061 & $(0.043)$ & 0.018 & $(0.063)$ \\
Self-employed $\cdot$ Log income & $0.008^{*}$ & $(0.004)$ & -0.002 & $(0.006)$ \\
Year fixed effects (omitted) & - & - & - & - \\
Constant & $0.166^{* * *}$ & $(0.055)$ & $0.031^{* *}$ & $(0.013)$ \\
& & & & \\
$N$ & 9,017 & & 9,017 & \\
\hline
\end{tabular}

Notes: Table reports average marginal effects from a bivariate probit estimation of equations (2) and (3). Means of OPTOUT and HOSPITAL are 0.041 and 0.085 , respectively. Bootstrapped standard errors (1000 replications) in parentheses. ${ }^{*} \mathrm{p}<0.1,{ }^{* *} \mathrm{p}<0.05,{ }^{* * *} \mathrm{p}<0.01$.

obese tend to favour private insurance and are more likely to become hospitalised. However, given that the marginal effects are small and statistically insignificant, the selection of obese individuals is negligible. The same applies to workers with a sick leave of more than six weeks, who tend to be more likely to choose private insurance and to be hospitalised. That workers with a sick leave seem to favour private insurance is somewhat unexpected, but it could result from the fact that not all private insurers collect information about sick leaves. With respect to the number of children, we can see that having more children correlates with a higher propensity to stay in public insurance, which is expected and in line with the institutional incentives. On the other hand, parents also turn out to be statistically significantly less likely to be hospitalised. These two observations seem to indicate that parents advantageously select public insurance. But, parents impose an additional cost on the public system through their children, who are insured free of charge. Overall, it is thus unclear whether parents are, on average, beneficial for the public sector budget. 
Table 3. Magnitude of Selection on Observables

\begin{tabular}{lcc}
\hline \hline & $\begin{array}{c}\text { Control for insurer } \\
\text { risk classification }\end{array}$ & $\begin{array}{c}\text { No controls } \\
\end{array}$ \\
& $(1)$ & $(2)$ \\
\hline$\hat{\rho}$ & $-0.088^{*}$ & $-0.130^{* * *}$ \\
LR test of $\rho=0$ (p-value) & 0.077 & 0.005 \\
$N$ & 9,017 & 9,017 \\
\hline Notes: Table reports the correlation of the residuals from bi- \\
variate probit estimations of equations $(2)$ and $(3) .{ }^{*} \mathrm{p}<0.1,{ }^{* *}$ \\
$\mathrm{p}<0.05, * * * \mathrm{p}<0.01$.
\end{tabular}

The magnitude of selection based on observables can be inferred from comparing the estimated correlation coefficients which are shown in the two columns of Table 3. Column 2 reports the estimates from a bivariate probit model of health insurance choice and health care utilisation in which the only independent variable is a constant. The correlation coefficient of this model shows the full extent of adverse selection against the public sector. The correlation coefficient of column 1 captures selection on unobservables, given that we control for the insurer risk classification. The difference between the two estimated correlation coefficients of columns 1 and 2 is due to the insurer risk classification and can be interpreted as a rough measure of the magnitude of selection on observables. According to this interpretation, adverse selection on observables accounts for approximately one third of the total adverse selection against the public sector.

\subsection{Selection on Unobservables}

As a first approach to selection on unobservables, we can infer its type from the sign of the estimated correlation coefficient in column 1 of Table 2. We see that, after controlling for the insurer risk classification, there remains a negative and statistically significant correlation between the choice to opt out of public insurance and subsequent hospitalisations. This negative correlation indicates the presence of adverse selection against public insurance based on unobservables. In this section, I present some factors that give rise to selection on unobservables.

To identify these factors, I follow the work of Finkelstein and Poterba (2014), who propose a way to identify sources of asymmetric information. Their idea relies on exploiting the information contained in unused observables, variables that are observed by the econometrician but which insurers do not observe or do not use in the premium calculation. These unused observables are included as additional independent variables in the bivariate probit model 
of health insurance choice and health care utilisation of the preceding section. If an unused observable is correlated with both health insurance choice and subsequent hospitalisations after controlling for the insurer risk classification, then it constitutes a source of selection on unobservables. ${ }^{10}$

I estimate the following bivariate probit model:

$$
\begin{aligned}
\text { OPTOUT }_{i t} & =\mathbf{1}\left(a_{1}+b_{1} X_{i t}+c_{1} Z_{i t}+e_{1 i t}>0\right) . \\
\text {HOSPITAL }_{i t+1} & =\mathbf{1}\left(a_{2}+b_{2} X_{i t}+c_{2} Z_{i t}+e_{2 i t}>0\right) .
\end{aligned}
$$

As before, OPTOUT $i t$ is a binary variable that captures the decision of individual $i$ to opt out of public insurance at time $t, \operatorname{HOSPITAL}_{i t+1}$ is a binary variable that equals one if individual $i$ is hospitalised in period $t+1$, and $X_{i t}$ contains variables that determine the relative price between public and private insurance for individual $i$ at time $t$. $Z_{i t}$ is a vector of unused observables to be described momentarily. The error terms $e_{i t}=\left(e_{1 i t}, e_{2 i t}\right)$ are assumed to be independently, identically, and normally distributed across individuals, but they may be correlated across time for a given individual.

Due to its survey nature, the SOEP contains many unused observables, which could all be included in $Z$. I concentrate on the five most promising candidates: self-assessed health, risk aversion, smoking status, weekly hours of work, and income. These variables can be expected to affect both health insurance choice and health care utilisation and may therefore constitute sources of selection on unobservables.

Self-assessed health should play an important role in the health insurance choice of forward-looking consumers and is moreover an accurate predictor of health-related risks (Idler and Benyamini 1997). It is reported on a five-point scale from one (=bad) to five (=excellent).

Risk aversion has been shown to correlate with both health insurance choice and health care utilisation (Finkelstein and McGarry 2006). It is reported on a scale from zero to ten, where individuals are asked to assess their aversion towards risk in general. ${ }^{11,12}$

Smoking status, which is somewhat surprisingly not elicited by private insurers, could have a similar effect as self-assessed health: smokers may refrain from buying private insurance if they anticipate that future health events lead to high out-of-pocket expenses. ${ }^{13}$

\footnotetext{
${ }^{10}$ This statement is conditional on the assumption that hospitalisations do not depend on insurance status. If this assumption is not valid, we cannot differentiate between sources of selection and sources of moral hazard.

${ }^{11}$ Dohmen et al. (2011) confirm that this question is a good measure of risk aversion in several domains.

${ }^{12}$ The question on risk aversion is contained in the questionnaires from 2004, 2006, and 2008 through 2011. I follow Bünnings and Tauchmann (2014) and others and consider risk preferences as fixed over time, using the average value of an individual's responses.

${ }^{13}$ Information on smoking behaviour is available every other year. Smoking status for the missing years is imputed as follows. If a person reports to smoke in the year before and the year after the information is missing, then this person is assumed to smoke in the year in between. Likewise if a person reports not to
} 
Long working hours are expected to have a negative impact on health and may also affect health insurance choice, because individuals who work long hours may prefer private insurance for its lower waiting times.

Finally, we may expect a positive correlation between income and health. Private insurers cannot take advantage of this correlation, however, because they are prohibited from using information about incomes to calculate premiums. As we already control for the income of self-employed individuals, through the interaction term in $X$, the income term included in $Z$ isolates the effect of income for dependent workers with incomes above the compulsory insurance threshold. A priori, it is unclear which type of insurance these workers prefer given that the relative price between public and private insurance is constant for them.

Table 4 reports the results from bivariate probit estimations of equations (4) and (5), where the standard errors are again computed using a block bootstrap procedure. The coefficient estimates of the insurer risk classification are not shown to save on space. ${ }^{14}$ Unused observables that enter equations (4) and (5) with coefficients of opposite sign are a source of adverse selection against public insurance based on unobservables. The preferred specification is shown in column 6. From it, we can infer that two unused observables matter for the selection between public and private insurance: self-assessed health and risk aversion.

Self-assessed health explains a part of the adverse selection against the public sector based on unobservables. After controlling for observables, individuals with higher self-assessed health have a lower risk of being hospitalised and are more likely to choose private insurance. This self-selection based on perceived health status is consistent with the idea that private insurers screen their customers. Healthy individuals choose private contracts with high deductibles, in return for actuarially low premiums, whereas sick individuals prefer public insurance, which involves moderate cost sharing. The inclusion of self-reported health in the model also affects the correlation of the residuals, albeit the impact is limited. The estimated correlation coefficient remains negative and significant, but it is approximately six percent smaller in absolute value than the estimate obtained in the preceding section.

Risk aversion is a source of advantageous selection on unobservables in favour of the public sector. After controlling for observables, risk-averse individuals are less willing to opt out of public insurance and less likely to be hospitalised. The latter finding has been documented before, i.a., in the context of the long-term care insurance market in the U.S. (Finkelstein and McGarry 2006). Regarding the choice of insurance in Germany, there are two reasons to believe that risk-averse individuals prefer public over private insurance. First, public insurance exposes insureds to less financial risk, on average, since out-of-pocket costs are typically lower in public insurance. Previous research has shown that this channel is quantitatively important (Finkelstein and McGarry 2006). Second, switching to private

smoke in two consecutive questionnaires. Smoking status is left undetermined otherwise.

${ }^{14}$ They are not substantially affected by the inclusion of the unused observables and available upon request. 
Table 4. Sources of Selection on Unobservables

\begin{tabular}{|c|c|c|c|c|c|c|}
\hline & (1) & $(2)$ & $(3)$ & (4) & (5) & (6) \\
\hline \multicolumn{7}{|c|}{ Dependent variable: OPTOUT } \\
\hline Self-assessed health & $\begin{array}{c}0.008^{* *} \\
(0.003)\end{array}$ & & & & & $\begin{array}{l}0.010^{* * *} \\
(0.003)\end{array}$ \\
\hline Risk aversion & & $\begin{array}{l}-0.005^{* * *} \\
(0.001)\end{array}$ & & & & $\begin{array}{l}-0.004^{* * *} \\
(0.001)\end{array}$ \\
\hline Smoking & & & $\begin{array}{l}0.015^{* * *} \\
(0.005)\end{array}$ & & & $\begin{array}{l}0.015^{* * *} \\
(0.005)\end{array}$ \\
\hline Weekly hours of work & & & & $\begin{array}{l}-0.002^{* *} \\
(0.001)\end{array}$ & & $\begin{array}{c}0.000 \\
(0.001)\end{array}$ \\
\hline Log income & & & & & $\begin{array}{l}-0.019^{* * *} \\
(0.004)\end{array}$ & $\begin{array}{l}-0.022^{* * *} \\
(0.004)\end{array}$ \\
\hline \multicolumn{7}{|c|}{ Dependent variable: HOSPITAL } \\
\hline Self-assessed health & $\begin{array}{l}-0.018^{* * *} \\
(0.004)\end{array}$ & & & & & $\begin{array}{l}-0.019^{* * *} \\
(0.005)\end{array}$ \\
\hline Risk aversion & & $\begin{array}{l}-0.005^{* *} \\
(0.002)\end{array}$ & & & & $\begin{array}{l}-0.006^{* * *} \\
(0.002)\end{array}$ \\
\hline Smoking & & & $\begin{array}{c}0.004 \\
(0.007)\end{array}$ & & & $\begin{array}{l}-0.000 \\
(0.007)\end{array}$ \\
\hline Weekly hours of work & & & & $\begin{array}{l}0.003^{* *} \\
(0.001)\end{array}$ & & $\begin{array}{c}0.003 \\
(0.002)\end{array}$ \\
\hline Log income & & & & & $\begin{array}{c}0.002 \\
(0.006)\end{array}$ & $\begin{array}{l}-0.002 \\
(0.007)\end{array}$ \\
\hline \multicolumn{7}{|c|}{ Correlation between $e_{1}$ and $e_{2}$ : } \\
\hline$\hat{\rho}$ & $-0.083^{*}$ & $-0.095^{*}$ & $-0.114^{* *}$ & $-0.086^{*}$ & $-0.083^{*}$ & $-0.111^{* *}$ \\
\hline LR test of $\rho=0$ (p-value) & 0.097 & 0.059 & 0.032 & 0.086 & 0.096 & 0.041 \\
\hline$N$ & 9,014 & 9,017 & 8,401 & 8,918 & 9,017 & 8,301 \\
\hline
\end{tabular}

Notes: Table reports average marginal effects of the unused observables and the correlation of the residuals from bivariate probit estimations of equations (4) and (5). Means of OPTOUT and HOSPITAL vary across columns. Bootstrapped standard errors (1000 replications) in parentheses. ${ }^{*} \mathrm{p}<0.1,{ }^{* *} \mathrm{p}<0.05$, $* * * \mathrm{p}<0.01$. 
insurance implies uncertainty about future premiums, as changes in family status translate into premium changes in private insurance. For example, a privately insured couple who become parents has to pay for their child in private health insurance, whereas the child is insured free of charge in public insurance.

Quantitatively, self-reported health and risk aversion have similar impacts: if both variables are included, the estimated correlation coefficient is approximately the same as the one of the preceding section, implying that the adverse selection against public insurance based on self-reported health and the advantageous selection in favour of public insurance based on risk aversion cancel each other out. ${ }^{15}$

Smoking, hours of work, and income do not represent sources of selection on unobservables because they are not statistically significantly correlated with both health insurance choice and hospitalisations after controlling for observables. While hours of work do significantly affect health insurance choice when they enter as the only unused observable (column 3), the effect is likely due to a spurious correlation with income. Once income is controlled for (column 6), the effect of hours of work on health insurance choice vanishes. For the same reason, we can expect the estimated positive coefficient of income on hospitalisations in column 4 to be biased, because hours of work are omitted in this specification. The preferred estimates (column 6) suggest that earning more and working fewer hours are inversely related to the probability of being hospitalised, as expected. There is no obvious explanation for the strong negative (positive) relationship between income (smoking) on the one hand and the choice of private insurance on the other hand. Finally, we can conclude that hours of work do not have the hypothesised impact on health insurance choice, and that smoking is unrelated to hospitalisations.

\subsection{Testing for Asymmetric Information}

The standard test of asymmetric information analyses the choice between two different insurance contracts, where one contract offers more generous coverage than the other, and the occurrence of subsequent risk events (Chiappori and Salanié 2000). With this approach, we reject the null hypothesis of symmetric information if the correlation of the residuals is statistically different from zero. In the present setting, however, individuals choose between public and private health insurance, which cannot be ordered by their coverage levels. Hence, we cannot proceed as usual.

Nevertheless, the model of public health insurance with opt-out presented in this paper offers a one-sided test of asymmetric information. Recalling Corollary 1, we can see that both a positive correlation of the residuals and a U-shaped relationship between health insurance choice and unobservable health status indicate the presence of asymmetric information,

\footnotetext{
${ }^{15}$ Results are not shown here, but available upon request.
} 
Table 5. Testing for Asymmetric Information

\begin{tabular}{lcccc}
\hline \hline & & & & \\
Dependent variable: & \multicolumn{2}{l}{ OPTOUT } & \multicolumn{3}{l}{ HOSPITAL } \\
\hline $\mathrm{SAH}=1$ & 0.005 & $(0.123)$ & 0.023 & $(0.027)$ \\
$\mathrm{SAH}=2$ & -0.006 & $(0.011)$ & 0.018 & $(0.011)$ \\
$\mathrm{SAH}=3$ (omitted) & - & - & - & - \\
$\mathrm{SAH}=4$ & 0.006 & $(0.005)$ & $-0.026^{* * *}$ & $(0.007)$ \\
$\mathrm{SAH}=5$ & $0.019^{* * *}$ & $(0.007)$ & $-0.028^{* *}$ & $(0.013)$ \\
& & & & \\
$N$ & 9,014 & & 9,014 & \\
\hline
\end{tabular}

Notes: Table reports average marginal effects of the five categories of self-assessed health obtained from a bivariate probit estimation of equations (4) and (5). 1=bad, $2=$ poor, $3=$ satisfactory, $4=$ good, $5=$ excellent. Means of OPTOUT and HOSPITAL are 0.041 and 0.085 , respectively. Bootstrapped standard errors (1000 replications) in parentheses. ${ }^{*} \mathrm{p}<0.1,{ }^{* *} \mathrm{p}<0.05,{ }^{* * *} \mathrm{p}<0.01$.

because both can only occur under asymmetric information.

The residuals are not positively correlated, as shown in Tables 3 and 4 . However, we may still conclude that there is asymmetric information, in case we find a U-shaped relationship between health insurance choice and unobservable health status. Self-assessed health is a natural candidate to test for such a relationship, given that it inherently is private information of the assessors. In order to pick up a potential nonmonotone effect of self-assessed health, I now replace the linear self-assessed health term in the model of the preceding section with indicators for the five categories of self-assessed health.

Table 5 shows estimated average marginal effects of the five indicators of self-assessed health after controlling for the insurer risk classification. The probability that a hospitalisation occurs strictly decreases in self-assessed health, suggesting that the residual information contained in self-assessed health is related to health status. On the other hand, the probability of opting out of public insurance is nonmonotonously related to self-assessed health: the relationship is U-shaped, where the probability of opting out of public insurance is lowest for individuals with a self-assessed health of two. According to the theoretical model, this U-shaped relationship indicates the presence of asymmetric information between private insurers and their clients. However, the probability of opting out of public insurance is imprecisely estimated because self-assessed health is heavily concentrated on the categories three and four. Therefore, the evidence in favour of information asymmetry should be interpreted as merely suggestive. 


\subsection{Discussion}

This section discusses potential threats to the validity of the empirical approach and examines the results' robustness. I conclude with a short discussion about measuring selection with physician visits.

I first want to return to the identifying assumption, which required that hospitalisations do not depend on health insurance status other than through selection. Besides anecdotal evidence and empirical support from the RAND Health Insurance Experiment, there is concrete evidence that this assumption holds up in the context of the German health insurance system. Hullegie and Klein (2010) exploit the compulsory insurance threshold in a regression discontinuity design, which allows to control for selection into public and private insurance. Using SOEP data, they find that hospitalisations are not related to the type of health insurance. Geil et al. (1997) and Riphahn et al. (2003), also using data from the SOEP, estimate count data models and provide further evidence in favour of the identifying assumption.

In addition to these studies, the hospitalisations of civil servants also support the validity of the identifying assumption. Civil servants have little reason to base their health insurance decision on health status given that they receive reimbursements of up to $80 \%$ of their medical expenses. Therefore, selection into health insurance should have a relatively small impact on the hospitalisations of civil servants, if any, and if the hospitalisations of civil servants depended on insurance status, we would attribute this dependence mainly to moral hazard or different access condition. Both simple two-sided t-tests and regressions that adjust for differences in observables do not reject the hypothesis that the hospitalisations of civil servants do not depend on insurance status. ${ }^{16}$ This suggests that moral hazard and different access conditions either do not affect hospitalisations or cancel each other out, both of which are in accordance with the identifying assumption.

The insurer risk classification is another point which deserves further discussion. To distinguish between selection on observables and selection on unobservables, it is necessary to control for all variables that determine the relative price between public and private insurance. In practice, however, this is not feasible due to data limitations. Some variables in the SOEP are less informative than the corresponding questions from the insurer questionnaires. For example, private insurers know not only whether a hospitalisation occurred, but also the reason for the hospitalisation. Moreover, some items from the insurer questionnaires are not included in the SOEP questionnaire, or they are included only in some years. For these reasons, I expect private insurers to have more information about insurance applicants than what is controlled for with the insurer risk classification in the preceding sections.

Having more detailed information about applicants, insurers will be able to classify individuals into narrower risk classes, leaving less room for unobserved heterogeneity within each

\footnotetext{
${ }^{16}$ The regression-adjusted p-value is 0.696 . Detailed results available upon request.
} 
class. Therefore, the estimates of selection on observables should be viewed as a lower bound, and the estimates of selection on unobservables should be viewed as an upper bound. Overall, selection into public insurance is unambiguously adverse given that individuals adversely select public insurance on both observables and unobservables.

I now demonstrate that the empirical results are robust to a number of potentially confounding factors. I first address the issue of unobserved heterogeneity, which has been dealt with so far by block bootstrapping the standard errors of the pooled probit models by individuals. In order to show that the pooled estimates are not driven by repeated observations on individuals who do not make an active decision between private and public health insurance, I reestimate the models of the preceding sections on the subsample of individuals who are in the first or second year of being eligible to choose private insurance.

To address the concern that the insurer risk classification does not include enough information about insurance applicants, I add two additional insuree characteristics: a physical component scale score and a mental component scale score. The two scales are described in detail in Andersen et al. (2007). They are available only for the even-numbered years from 2002 onwards, and I linearly impute them for the odd-numbered years in between. Almost certainly, private insurers will not use these scales to calculate premiums. But, the scales may pick up effects of other variables that are missing in the SOEP data but observed by insurers.

To assess the dependent variable HOSPITAL from the baseline model, which is an indicator that equals one if a person is hospitalised in the year after the choice between public and private insurance, I consider two alternatives. The first alternative is an indicator which equals one if a person is hospitalised within two years after health insurance choice. The second alternative is an indicator which equals one if a person is hospitalised from period $t+1$ onwards until the end of the sample period.

To address potential measurement errors in income in the SOEP data, a point which has been raised by Hullegie and Klein (2010), I reestimate the models on the subsamples of individuals with incomes of 5,000 and 10,000 Euro, respectively, above the compulsory insurance threshold. The results of this robustness check and those explained above are collected in Tables 6-8 in the Appendix. The qualitative conclusions of the preceding two sections do not change in any of the alternative specifications. Due to large variations in the number of observations under different specifications, the estimates' statistical significance departs sometimes from those of the baseline estimates.

So far, I have measured selection exclusively with respect to subsequent hospitalisations. But, hospitalisations represent only one dimension on which private insurers may be able to favourably select their clients. The SOEP contains also information about doctor visits. I reestimate the models of the preceding sections with an indicator of doctor visits replacing the hospitalisation indicator. Before turning to the results, it is important to note that physician 
visits are unlikely to capture only selection. Instead, doctor visits are often discretionary and subject to moral hazard by patients. Arguably, doctor visits are more expensive, on average, for privately insured than for publicly insured patients, because private insurance involves more cost sharing. Given the difference in cost sharing, moral hazard should lead to a more negative correlation of the residuals.

Table 9 in the Appendix contains the results of bivariate probit models with doctor visits included in lieu of hospitalisations. The estimates indicate a more negative correlation of the residuals, suggesting the presence of moral hazard for physician visits. This is in line with the findings of Hullegie and Klein (2010), who also find evidence of moral hazard in physician visits. Self-assessed health and risk aversion, after controlling for the insurer risk classification, do not explain doctor visits.

\section{Conclusion}

There are a number of benefits associated to public health insurance with opt-out. The benefits include the socialisation of risks and redistribution of incomes in public insurance visà-vis a system relying only on private health insurance, public insurance being an insurance of last resort to the seriously sick and to the poor, a reduced number of insureds having double coverage compared to a tax-financed public health insurance plan, and the increased competition for clients, which creates strong incentives for public health insurance providers to increase efficiency and quality.

These benefits have to be weighed against one major drawback: the potential for adverse selection against public insurance. This paper shows that adverse selection against the public sector does not have to be a defining property of public health insurance with opt-out. However, the evidence for Germany suggests that private insurers have a competitive advantage over public health insurance providers under current legislation. This competitive imbalance affects adversely the low-income earners, who are mandatorily insured in public insurance and have to bear the increase in contributions due to the outflow of good risks into private insurance. To conclude this paper, I briefly discuss two policies which aim at levelling the playing field between public and private health insurance providers in Germany.

One widely endorsed policy are risk-adjusted transfers between public and private insurers (Kifmann and Nell 2013, Grunow and Nuscheler 2014). Risk adjustment would eliminate the selection on observables that we observe under the current system. The U.S. experience with Medicare Advantage has moreover shown that a sufficiently elaborate risk adjustment mechanism is also effective in keeping selection on unobservables to a minimum (Newhouse et al. 2012). Adding to the potential benefits, implementation of such a risk adjustment mechanism would be relatively inexpensive given that Germany could build on an existing mechanism, which compensates public health insurance providers for differences in their risk 
pools. The existing risk adjustment mechanism has been found to be generally effective (Nuscheler and Knaus 2005), albeit there is evidence that insurers select risks based on geography, which is not included in the risk adjustment formula (Bauhoff 2012).

Given that selection on unobservables accounts for up to two thirds of the total adverse selection against public insurance, policies that reduce selection on unobservables are essential. Relaxing the restrictions that public health insurance providers face with respect to the design of insurance policies could prove to be one such policy, because it would allow public health insurance providers to compete with private insurers for low-risk clients, through offering contracts with high deductibles and low premiums. In 2007, Germany made a first step in this direction. Since then, public health insurance providers are allowed to offer socalled choice policies, which can include certain sizes of deductibles and rebates. To the best of my knowledge, there is no evidence on how this regulatory change has affected selection. Assessing the impact of the 2007 health insurance reform could thus be an interesting topic for future research. 


\section{References}

Akerlof, G. A. (1970) The market for "lemons": quality uncertainty and the market mechanism, Quarterly Journal of Economics, 84, 488-500.

Andersen, H. H., Nübling, M., Mühlbacher, A., Schupp, J. and Wagner, G. G. (2007) Computation of standard values for physical and mental health scale scores using the SOEP version of SF12v2, Journal of Applied Social Science Studies, 127, 171-182.

Bauhoff, S. (2012) Do health plans risk-select? an audit study on germany's social health insurance, Journal of Public Economics, 96, 750-759.

Brown, J., Duggan, M., Kuziemko, I. and Woolston, W. (2014) How does risk selection respond to risk adjustment? new evidence from the medicare advantage program, American Economic Review, 104, 3335-3364.

Bünnings, C. and Tauchmann, H. (2014) Who opts out of the statutory health insurance? a discrete time hazard model for germany, Health Economics, pp. n/a-n/a.

Chiappori, P.-A. and Salanié, B. (2000) Testing for asymmetric information in insurance markets, Journal of Political Economy, 108, 56-78.

Cohen, A. and Siegelman, P. (2010) Testing for adverse selection in insurance markets, Journal of Risk and Insurance, 77, 39-84.

Colombo, F. and Tapay, N. (2004) Private health insurance in OECD countries: the benefits and costs for individuals and health systems, OECD Health Working Paper 15.

de la Mata, D., Machado, M. P. and Valdés, M. N. (2014) Hide and seek: asymmetric information in the chilean private health insurance market, unpublished manuscript.

Dohmen, T., Falk, A., Huffman, D., Sunde, U., Schupp, J. and Wagner, G. G. (2011) Individual risk attitudes: measurement, determinants, and behavioral consequences, Journal of the European Economic Association, 9, 522-550.

Einav, L., Finkelstein, A. and Levin, J. (2010) Beyond testing: empirical models of insurance markets, Annual Review of Economics, 2, 311-336.

Finkelstein, A. and McGarry, K. (2006) Multiple dimensions of private information: evidence from the long-term care insurance market, American Economic Review, 96, 938-958.

Finkelstein, A. and Poterba, J. (2014) Testing for asymmetric information using "unused observables" in insurance markets: evidence from the u.k. annuity market, Journal of Risk and Insurance, 81, 709-734. 
Geil, P., Million, A., Rotte, R. and Zimmermann, K. F. (1997) Economic incentives and hospitalization in germany, Journal of Applied Econometrics, 12, 295-311.

Goulão, C. (2015) Voluntary public health insurance, Public Choice, 162, 135-157.

Grunow, M. and Nuscheler, R. (2014) Public and private health insurance in germany: the ignored risk selection problem, Health Economics, 23, 670-687.

Hindriks, J. and De Donder, P. (2003) The politics of redistributive social insurance, Journal of Public Economics, 87, 2639-2660.

Hullegie, P. and Klein, T. J. (2010) The effect of private health insurance on medical care utilization and self-assessed health in germany, Health Economics, 19, 1048-1062.

Idler, E. L. and Benyamini, Y. (1997) Self-rated health and mortality: a review of twentyseven community studies, Journal of Health and Social Behavior, 38, 21.

Kifmann, M. and Nell, M. (2013) Fairer systemwettbewerb zwischen gesetzlicher und privater krankenversicherung, Hamburg center for health economics research paper.

Manning, W. G., Newhouse, J. P., Duan, N., Keeler, E. B., Leibowitz, A. and Marquis, M. S. (1987) Health insurance and the demand for medical care: Evidence from a randomized experiment, American Economic Review, 77, 251-77.

Newhouse, J. P., Price, M., Huang, J., McWilliams, J. M. and Hsu, J. (2012) Steps to reduce favorable risk selection in medicare advantage largely succeeded, boding well for health insurance exchanges, Health Affairs, 31, 2618-2628.

Nuscheler, R. and Knaus, T. (2005) Risk selection in the german public health insurance system, Health Economics, 14, 1253-1271.

Olivella, P. and Vera-Hernández, M. (2013) Testing for asymmetric information in private health insurance, Economic Journal, 123, 96-130.

Riley, J. G. (1985) Competition with hidden knowledge, Journal of Political Economy, 93, 958-976.

Riphahn, R. T., Wambach, A. and Million, A. (2003) Incentive effects in the demand for health care: a bivariate panel count data estimation, Journal of Applied Econometrics, 18, $387-405$.

Rothschild, M. and Stiglitz, J. (1976) Equilibrium in competitive insurance markets: an essay on the economics of imperfect information, Quarterly Journal of Economics, 90, 629-649. 


\section{Appendix}

The following three tables document that the empirical results are qualitatively unaffected by the possibly confounding factors which are discussed in Section 5.5 of the main text. Table 6 shows that there is robust evidence of adverse selection against public insurance based on both observables and unobservables. Table 7 demonstrates that the self-selection based on self-assessed health and risk aversion is robust. Table 8 illustrates that there is robust, albeit imprecisely estimated, evidence of asymmetric information.

Table 6. Robustness Checks: Selection on Observables and Unobservables

\begin{tabular}{lcccccc}
\hline \hline & & & & & & \\
\multicolumn{1}{c}{$(1)$} & $(2)$ & $(3)$ & $(4)$ & $(5)$ & $(6)$ \\
\hline Panel A. Control for insurer risk classification & & & & \\
$\hat{\rho}$ & $-0.198^{* *}$ & -0.032 & -0.050 & -0.019 & -0.061 & -0.048 \\
LR test of $\rho=0$ (p-value) & 0.024 & 0.595 & 0.227 & 0.589 & 0.257 & 0.392 \\
& & & & & & \\
Panel B. No controls & & & & & & \\
$\hat{\rho}$ & $-0.242^{* * *}$ & -0.070 & $-0.086^{* *}$ & $-0.075^{* *}$ & $-0.118^{* *}$ & $-0.104^{* *}$ \\
LR test of $\rho=0$ (p-value) & 0.002 & 0.204 & 0.026 & 0.014 & 0.017 & 0.044 \\
& & & & & & \\
$N$ & 2,295 & 6,109 & 8,275 & 9,159 & 7,209 & 6,141 \\
\hline
\end{tabular}

Notes: Table reports the correlation of the residuals from bivariate probit estimations of equations (2) and (3). Panel A (B) includes (excludes) the insurer risk classification. Column 1 shows estimates for the subsample of individuals who are in the first or second year of being eligible to choose private insurance. Column 2 shows estimates after controlling for two additional insuree characteristics: a mental component scale and a physical component scale. The dependent variable HOSPITAL in the bivariate probit model whose estimates are reported in column 3 is an indicator which equals one if a person is hospitalised within in two years after his opt out decision. The dependent variable HOSPITAL in the bivariate probit model whose estimates are reported in column 4 is an indicator which equals one if a person is hospitalised within the period from $t+1$ onwards until the end of the sample period. Column 5 (6) shows estimates for the subsample of individuals who are self-employed and/or have incomes of 5,000 (10,000) Euros above the compulsory insurance threshold. * $\mathrm{p}<0.1,{ }^{* *} \mathrm{p}<0.05, * * * \mathrm{p}<0.01$. 


\begin{tabular}{lllllll}
\hline \hline & & & & & & \\
& $(1)$ & $(2)$ & $(3)$ & $(4)$ & $(5)$ & $(6)$ \\
\hline Dependent variable: OPTOUT & & & & & & \\
Self-assessed health & 0.012 & $0.012^{* *}$ & $0.008^{* *}$ & $0.007^{* *}$ & $0.007^{* *}$ & $0.008^{*}$ \\
& $(0.008)$ & $(0.005)$ & $(0.003)$ & $(0.003)$ & $(0.004)$ & $(0.004)$ \\
Risk aversion & $-0.006^{*}$ & $-0.004^{* *}$ & $-0.005^{* * *}$ & $-0.004^{* * *}$ & $-0.004^{* * *}$ & $-0.005^{* *}$ \\
& $(0.004)$ & $(0.002)$ & $(0.001)$ & $(0.001)$ & $(0.002)$ & $(0.002)$ \\
& & & & & & \\
Dependent variable: HOSPITAL & & & & & & \\
Self-assessed health & -0.012 & -0.007 & $-0.029^{* * *}$ & $-0.026^{* * *}$ & $-0.021^{* * *}$ & $-0.021^{* * *}$ \\
& $(0.008)$ & $(0.007)$ & $(0.006)$ & $(0.010)$ & $(0.005)$ & $(0.005)$ \\
Risk aversion & -0.002 & $-0.006^{* * *}$ & $-0.008^{* *}$ & -0.008 & $-0.005^{* *}$ & $-0.005^{* *}$ \\
& $(0.004)$ & $(0.002)$ & $(0.003)$ & $(0.006)$ & $(0.002)$ & $(0.002)$ \\
$N$ & & & & & & \\
\hline
\end{tabular}

Notes: Table reports average marginal effects of self-assessed health and risk aversion obtained from bivariate probit estimations of equations (4) and (5). Column 1 shows estimates for the subsample of individuals who are in the first or second year of being eligible to choose private insurance. Column 2 shows estimates after controlling for two additional insuree characteristics: a mental component scale and a physical component scale. The dependent variable HOSPITAL in the bivariate probit model whose estimates are reported in column 3 is an indicator which equals one if a person is hospitalised within in two years after his opt out decision. The dependent variable HOSPITAL in the bivariate probit model whose estimates are reported in column 4 is an indicator which equals one if a person is hospitalised within the period from $t+1$ onwards until the end of the sample period. Column 5 (6) shows estimates for the subsample of individuals who are self-employed and/or have incomes of 5,000 (10,000) Euros above the compulsory insurance threshold. Means of OPTOUT and HOSPITAL vary across columns. Bootstrapped standard errors (1000 replications) in parentheses. ${ }^{*} \mathrm{p}<0.1,{ }^{* *} \mathrm{p}<0.05,{ }^{* * *} \mathrm{p}<0.01$. 
Table 8. Robustness Checks: Testing for Asymmetric Information

\begin{tabular}{|c|c|c|c|c|c|c|}
\hline & (1) & $(2)$ & (3) & $(4)$ & (5) & $(6)$ \\
\hline \multicolumn{7}{|c|}{ Dependent variable: OPTOUT } \\
\hline $\mathrm{SAH}=1$ & $\begin{array}{c}0.012 \\
(0.343)\end{array}$ & $\begin{array}{l}-0.015 \\
(0.174)\end{array}$ & $\begin{array}{c}0.006 \\
(0.126)\end{array}$ & $\begin{array}{c}0.004 \\
(0.118)\end{array}$ & $\begin{array}{c}0.013 \\
(0.142)\end{array}$ & $\begin{array}{c}0.013 \\
(0.147)\end{array}$ \\
\hline $\mathrm{SAH}=2$ & $\begin{array}{l}-0.015 \\
(0.063)\end{array}$ & $\begin{array}{l}-0.016 \\
(0.014)\end{array}$ & $\begin{array}{l}-0.007 \\
(0.011)\end{array}$ & $\begin{array}{l}-0.006 \\
(0.011)\end{array}$ & $\begin{array}{l}-0.008 \\
(0.014)\end{array}$ & $\begin{array}{l}-0.008 \\
(0.014)\end{array}$ \\
\hline $\mathrm{SAH}=3$ (omitted $)$ & - & - & - & - & - & - \\
\hline $\mathrm{SAH}=4$ & $\begin{array}{c}0.004 \\
(0.015)\end{array}$ & $\begin{array}{c}0.013^{*} \\
(0.007)\end{array}$ & $\begin{array}{c}0.005 \\
(0.005)\end{array}$ & $\begin{array}{c}0.006 \\
(0.005)\end{array}$ & $\begin{array}{c}0.005 \\
(0.006)\end{array}$ & $\begin{array}{c}0.006 \\
(0.007)\end{array}$ \\
\hline $\mathrm{SAH}=5$ & $\begin{array}{c}0.028 \\
(0.019)\end{array}$ & $\begin{array}{c}0.022^{*} \\
(0.012)\end{array}$ & $\begin{array}{l}0.020^{* * *} \\
(0.008)\end{array}$ & $\begin{array}{l}0.018^{* *} \\
(0.007)\end{array}$ & $\begin{array}{c}0.019^{* *} \\
(0.009)\end{array}$ & $\begin{array}{l}0.020^{* *} \\
(0.009)\end{array}$ \\
\hline \multicolumn{7}{|c|}{ Dependent variable: HOSPITAL } \\
\hline $\mathrm{SAH}=1$ & $\begin{array}{l}-0.073 \\
(0.329)\end{array}$ & $\begin{array}{l}-0.014 \\
(0.043)\end{array}$ & $\begin{array}{l}-0.013 \\
(0.044)\end{array}$ & $\begin{array}{l}-0.070 \\
(0.054)\end{array}$ & $\begin{array}{c}0.039 \\
(0.028)\end{array}$ & $\begin{array}{c}0.016 \\
(0.031)\end{array}$ \\
\hline $\mathrm{SAH}=2$ & $\begin{array}{l}-0.000 \\
(0.022)\end{array}$ & $\begin{array}{c}0.014 \\
(0.014)\end{array}$ & $\begin{array}{c}0.036^{* *} \\
(0.017)\end{array}$ & $\begin{array}{c}0.043^{*} \\
(0.023)\end{array}$ & $\begin{array}{c}0.022^{*} \\
(0.012)\end{array}$ & $\begin{array}{c}0.012 \\
(0.014)\end{array}$ \\
\hline $\mathrm{SAH}=3$ (omitted) & - & - & - & - & - & - \\
\hline $\mathrm{SAH}=4$ & $\begin{array}{l}-0.018 \\
(0.014)\end{array}$ & $\begin{array}{l}-0.023^{* *} \\
(0.010)\end{array}$ & $\begin{array}{l}-0.036^{* * *} \\
(0.011)\end{array}$ & $\begin{array}{l}-0.033^{* *} \\
(0.016)\end{array}$ & $\begin{array}{l}-0.027^{* * *} \\
(0.008)\end{array}$ & $\begin{array}{l}-0.031^{\text {*** }} \\
(0.009)\end{array}$ \\
\hline $\mathrm{SAH}=5$ & $\begin{array}{c}-0.037^{*} \\
(0.022)\end{array}$ & $\begin{array}{c}0.014 \\
(0.016)\end{array}$ & $\begin{array}{l}-0.044^{* *} \\
(0.018)\end{array}$ & $\begin{array}{l}-0.040 \\
(0.026)\end{array}$ & $\begin{array}{c}-0.026^{*} \\
(0.014)\end{array}$ & $\begin{array}{l}-0.036^{* *} \\
(0.015)\end{array}$ \\
\hline$N$ & 2,295 & 6,108 & 8,272 & 9,154 & 7,207 & 6,139 \\
\hline
\end{tabular}

Notes: Table shows average marginal effects of the five outcomes of self-assessed health obtained from bivariate probit estimations of equations (4) and (5). $1=$ bad, $2=$ poor, $3=$ satisfactory, $4=$ good, $5=$ excellent. Column 1 shows estimates for the subsample of individuals who are in the first or second year of being eligible to choose private insurance. Column 2 shows estimates after controlling for two additional insuree characteristics: a mental component scale and a physical component scale. The dependent variable HOSPITAL in the bivariate probit model whose estimates are reported in column 3 is an indicator which equals one if a person is hospitalised within in two years after his opt out decision. The dependent variable HOSPITAL in the bivariate probit model whose estimates are reported in column 4 is an indicator which equals one if a person is hospitalised within the period from $t+1$ onwards until the end of the sample period. Column 5 (6) shows estimates for the subsample of individuals who are self-employed and/or have incomes of 5,000 (10,000) Euros above the compulsory insurance threshold. Means of OPTOUT and HOSPITAL vary across columns. Bootstrapped standard errors (1000 replications) in parentheses. ${ }^{*} \mathrm{p}<0.1,{ }^{* *} \mathrm{p}<0.05,{ }^{* * *} \mathrm{p}<0.01$. 
Table 9 contains estimates from bivariate probit models that include doctor visits, instead of hospitalisations, in the equation capturing the utilisation of medical services.

Table 9. Measuring Selection with Doctor Visits

\begin{tabular}{|c|c|c|c|c|c|c|}
\hline & $(1)$ & $(2)$ & $(3)$ & (1) & $(2)$ & $(3)$ \\
\hline Dependent variable: & \multicolumn{3}{|c|}{ OPTOUT } & \multicolumn{3}{|c|}{ DOCTORVISIT } \\
\hline $\mathrm{SAH}$ & \multicolumn{3}{|c|}{$\begin{array}{l}0.007^{* *} \\
(0.003)\end{array}$} & \multicolumn{3}{|c|}{$\begin{array}{l}-0.011 \\
(0.008)\end{array}$} \\
\hline $\mathrm{SAH}=1$ & & & $\begin{array}{c}0.005 \\
(0.130)\end{array}$ & & & $\begin{array}{l}-0.107^{*} \\
(0.064)\end{array}$ \\
\hline $\mathrm{SAH}=2$ & & & $\begin{array}{l}-0.006 \\
(0.010)\end{array}$ & & & $\begin{array}{c}0.025 \\
(0.022)\end{array}$ \\
\hline $\mathrm{SAH}=3($ omitted $)$ & & & - & & & - \\
\hline $\mathrm{SAH}=4$ & & & $\begin{array}{c}0.006 \\
(0.005)\end{array}$ & & & $\begin{array}{l}-0.013 \\
(0.012)\end{array}$ \\
\hline $\mathrm{SAH}=5$ & & & $\begin{array}{c}0.018^{* *} \\
(0.007)\end{array}$ & & & $\begin{array}{l}-0.026 \\
(0.020)\end{array}$ \\
\hline Risk aversion & & $\begin{array}{l}-0.004^{* * *} \\
(0.001)\end{array}$ & & & $\begin{array}{c}0.001 \\
(0.004)\end{array}$ & \\
\hline \multicolumn{7}{|c|}{ Correlation between $e_{1}$ and $e_{2}$ : } \\
\hline$\hat{\rho}$ & $-0.099 * * *$ & $-0.097^{* * *}$ & $-0.097 * * *$ & $-0.099^{* * *}$ & $-0.097^{* * *}$ & $-0.097 * * *$ \\
\hline LR test of $\rho=0$ (p-value) & 0.002 & 0.003 & 0.003 & 0.002 & 0.003 & 0.003 \\
\hline$N$ & 9,031 & 9,028 & 9,028 & 9,031 & 9,028 & 9,028 \\
\hline
\end{tabular}

Notes: Column 1 reports the correlation of the residuals from a bivariate probit estimation of equations (2) and (3), where the dependent variable in equation (3) is an indicator which equals one if the person has visited a physician in the three months prior to the interview in period $t+1$. Columns 2 and 3 report average marginal effects of self-assessed health and risk aversion and the correlation of the residuals from bivariate probit estimations of equations (4) and (5), where the dependent variable in equation (5) is an indicator which equals one if the person has visited a physician in the three months prior to the interview in period $t+1$. Means of OPTOUT and DOCTORVISIT vary across columns. Bootstrapped standard errors (1000 replications) in parentheses. ${ }^{*} \mathrm{p}<0.1,{ }^{* *} \mathrm{p}<0.05,{ }^{* * *} \mathrm{p}<0.01$. 